\title{
Simulation Based Validation of Range Prediction of Electric Vehicles
}

\author{
Mohammed Rabhi' ${ }^{1}$ Imre Zsombók ${ }^{1 *}$ \\ 1 Department of Automotive Technologies, Faculty of Transportation Engineering and Vehicle Engineering, Budapest University \\ of Technology and Economics, H-1521 Budapest, P. O. B. 91, Hungary \\ * Corresponding author, e-mail: zsombok@ak-s.hu
}

Received: 04 October 2019, Accepted: 19 November 2019, Published online: 28 February 2022

\begin{abstract}
With the increasing environmental pollution in our urban communities along with the continuous exhaustion of oil assets, electric vehicles are ending up profoundly supported as means of transport. There is a proceeding with increment in the quantity of EVs being used, however their global expansion and acceptance by consumers is identified with the performance they can deliver. The most significant highlights here are observably the low energy density, with staggering expenses and short cycle life bringing about constrained mileage contrasted with conventional passenger vehicles. Ordinarily, in the technical specifications of electric cars, automakers give an operational combined range which isn't completely accurate and doesn't differentiate and take into consideration several influencing factors (urban driving or inter city traffic, ambient temperature, utilization of auxiliary equipment ...). For the owners it is imperative to know as accurate as possible the remaining range and influence of the auxiliaries on energy consumption and mileage. That information will guarantee a tranquil and pleasant journey regardless of the constrained range of electric vehicles.
\end{abstract} Keywords

electric vehicles, driving cycles, simulation

\section{Introduction}

The vehicle industry is at present at the focal point of a worldwide change, driven by four key patterns: Electrification, self-driving cars, car sharing and connected vehicles. While every one of these interconnected patterns is as of now obvious in day by day life, their full sending has not yet been ensured, nor has been the speed of take-up.

Electric mobility is getting significant attention in Europe and many other regions. Car manufacturers, consumers and grid operators show an increasing interest in the transition towards electric vehicles as renewable fuels seemingly can not solve the decarbonisation problem (Zöldy, 2009). Since electric vehicles produce extremely low emissions (both acoustical and particle outflows (Ivković et al., 2018) and since their top speed is constrained, they are perfect for use in urban regions with high environmental restrictions (Antonya et al., 2015). Therefore, the popularity and attractiveness of EV's is raised.

However, even technical framework conditions must be created to increase the acceptance of electric vehicles. There are exceptional difficulties in infrastructure development and the inherent limitations of the energy storage advancements (Široký et al., 2017). In this setting drivers of EV's are disrupted by the imprecise mileage prediction (Polak, 2018). The mentioned reasons cause a major disarray among clients and diminish the attractive quality. As fuel and/or electricity are one of the major running cost contributors (Gao et al., 2019) the prediction should be as precise as possible. In any case, figures state that the interest for electric mobility is increasing (Török et al., 2014). Thus, it is required to increase the accuracy of range prediction models to progress toward a better state of art and a more substantial market presence.

\section{Literature review}

The forecast of realizable EV mileage by and large relies upon three noteworthy classes of factors:

- vehicle structure,

- driver

- and environment condition. 
Research on this point appears that every one of these classes relies upon the variety of direct or indirect parameters (Bi et al., 2018; Mruzek et al., 2016). Some of the parameters that have a steady input (e.g., vehicle type, transmission type, number of seats, mass, weight) are similar as in case of traditional internal combustion engine vehicles (Zöldy, 2019), other steady inputs (such as battery capacity, infrastructure, accessibility of charging stations, charging time, etc.) are similar to conventional ones but have a different dimension and different parameters are inconstant (battery SOC, battery health condition - SOH, driver conduct, traffic stream (Sentoff et al., 2015), EV dynamic execution, Battery Management System (BMS), interior temperature, exterior environment conditions, every one of them affect the EV's mileage (Fig. 1).

In any case, most of the conducted researches are related to the linear approximation of the maximal achievable range by electric vehicle dependent on the approximation of real-time charge of the battery (Török and Zöldy, 2010).

The evaluation of practical status of the storage capacity is performed primarily by examining two fundamental parameters: level of the battery charge (SOC) and the cells' health state (SOH). The first parameter is determined utilizing data on the voltage, current and temperature values, and the cells' health state is determined dependent on the electrochemical degradation process within the battery cells (which decreases the recharging limit and accessible energy). Since discharging and charging the battery includes complex physical and chemical processes (Yuksel and Michalek, 2015), it's anything but a simple assignment to gauge the estimation of the $\mathrm{SOH}$ parameter precisely. The direct prediction of an EV mileage relies upon the precision of the SOC value. As this gives essential data about the measure of accessible energy to be utilized by the EV's powertrain. In this way, the precision of prediction is a significant factor in picking and actualizing a SOC estimation strategy inside an EV's frameworks.

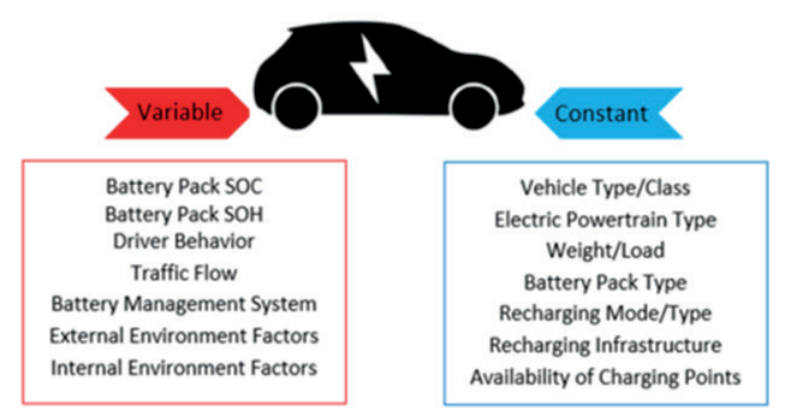

Fig. 1 Constant and variable factors influencing electric vehicles' range
There are several approaches to demonstrate drivers conduct (Varga et al., 2019). Another methodology is to utilize a Data-Driven technique to demonstrate confident driver's conduct. Results show that customized path inclinations are derived straightforwardly from the observed drivers' driving styles, utilizing a reversed learning strategy. Thus, the proposed model can foresee courses as indicated by driver inclinations. Unfortunately, it doesn't forecast the effect of heating, ventilation, and air conditioning utilization by the driver. In any case, this methodology presents a probabilistic guide for possible destinations. It comprises two models: the artificial neural Network Model (NN) and the Multiple Linear Regression (MLR) model. The second approach is utilized to assess the energy consumption (given a few indicator factors), while the neural network forecasts the unknown indicator factors of the regression model. Regarding the acquired outcomes, the suggested model has a forecasting capability on energy utilization with $12-14 \%$ of mean total error.

Other techniques are utilized to demonstrate the impacts of the vehicle driver's conduct on effectiveness of electric vehicle utilization, considering about a little measure of test data (interestingly with the data-driven techniques above). A way to deal with this could be based on the outcomes acquired identifying the impact of driver's conduct on decreasing fuel utilization for a vehicle with internal combustion engine, by creating and utilizing a control-based driving style model (Delling et al., 2015). A semi-learning technique was utilized to enhance the style of the human driver related factors, utilizing the simplex technique. Three driving styles were proposed as the model's most important component: dynamic driving, normal driving and eco driving.

Multiple influencing factors are combined in a standalone model. One approach to deal with numerous elements simultaneously is to allocate them to a discrete road section (Javanmardi et al., 2017). Regularly, such a discretization procedure is utilized in online maps. Road network representation could be a graph. Every road fragment is characterized by explicit properties, and for the range expectation issue, the properties are the direct factors that impact an electric vehicle's range, for example, density of the traffic, air conditions, geography, etc. A new method that aims to work with huge scale road networks was created to perform calculations productively (Baum et al., 2016). Supplementary, different researchers stretched out the algorithm to deal with negative cycle costs triggered by the recovery of energy, specific 
to electric vehicle usage conditions (Oliva et al., 2013). For the considered sections, the researchers characterized a cost capacity $f(\operatorname{arc})$, which is equivalent to the measure of energy required to pass along the road segment arc. Summation of expenses along the way is equivalent to the aggregate measure of energy essential to reach the destination. Inappropriately, the used technique does not consider driver's conduct, which decreases its functionality. Be that as it may, the graph portrayal is efficient and normally utilized to manage road-grid linked issues, for example, map generation and route definition.

A model-based methodology for driving distance estimation was created by joining particle filter with Markov chains. Mileage prediction is described as a probability distribution function, estimated by a set of weighted particles. The methodology incorporates explicit models of the energy storage, e-drive and vehicle dynamics only, and takes various inputs into consideration, such as inconstancy of the driving profile performed through simulation (Ziebart et al., 2008). Researchers express that the chosen methodology forecasts the electric vehicles' remaining mileage with moderate precision and calculation resource need.

WLTP limitations are only discussed from the legislative and economical perspective (Zöldy, 2018), nothing was addressed from technical side, so far, it's still in a demo phase and provides overall better and more accurate results than the NEDC. Our research work's main aim is to model and simulate the WLTC test cycle and to extend it with real world vehicle data for an electric vehicle.

\section{Materials and methods}

An electric vehicle model has been created in IPG CarMaker software. The constructed model is based on the existing Mercedes-Benz Class B 250e. The model has been simulated with various properties for batteries, electric motors, transmission, aerodynamics of the vehicle, and driver properties to acquire data regarding vehicle performance, energy consumption and range on the new WLTC test cycle and compare it to the previous NEDC Cycle.

\subsection{IPG CarMaker simulation}

IPG CarMaker is a simulation software used to create and simulate an actual vehicle. The vehicle is created using a mathematical model that contains all the physical parameters of the car and its properties, the 3D environment, maneuver instructions, driving presets and style.
More than 30 simulations have been performed in different scenarios, taking into consideration different battery SOC, driver behavior, load and auxiliaries. Data was collected and analyzed in IPG control, the simulation was monitored using IPG Movies and IPG Instrument.

In order to simulate the range of our MB250e, the initial case begins with a fully charged battery, so SOC is $100 \%$ in the first case, then it was set to $60 \%$ and $30 \%$ respectively (Table 1). After every simulation, results were recorded, battery, current and energy consumption were monitored via IPGControl (Fig. 2).

The simulation ends, the vehicle stops, the state of charge is then changed, and new results are analyzed. We shift between a normal driver behavior to an energy efficient approach and compare the results (Fig. 3), then we take into consideration auxiliaries' consumption in the HV Battery. We estimated this consumption at $1 \mathrm{~kW}$ (Conservative Selection).

After a couple of simulations, we launched the driver adaption, where the driver goes through the road to learn, adapt and improve the overall performance. Then we repeated the simulations for optimized results (Driver was set to Normal). Results of the simulations are presented in Table 2.

Table 1 Simulation cases

\begin{tabular}{lccc}
\hline Cases & $\begin{array}{c}\text { Battery Power } \\
(\mathrm{kWh})\end{array}$ & $\begin{array}{c}\text { Battery SOC } \\
(\%)\end{array}$ & $\begin{array}{c}\text { Vehicle Mass at } \\
70 \mathrm{~kg}\end{array}$ \\
\hline Case 1 & $28 \mathrm{kWh}$ & $100 \%$ & $1849.87 \mathrm{~kg}$ \\
Case 2 & $28 \mathrm{kWh}$ & $60 \%$ & $1849.87 \mathrm{~kg}$ \\
Case 3 & $28 \mathrm{kWh}$ & $30 \%$ & $1849.87 \mathrm{~kg}$ \\
\hline \multirow{2}{*}{ Cases } & Battery Power & Battery SOC & Vehicle Mass at \\
& $(\mathrm{kWh})$ & $(\%)$ & $140 \mathrm{~kg}$ \\
\hline Case 4 & $28 \mathrm{kWh}$ & $100 \%$ & $1919.87 \mathrm{~kg}$ \\
Case 5 & $28 \mathrm{kWh}$ & $60 \%$ & $1919.87 \mathrm{~kg}$ \\
Case 6 & $28 \mathrm{kWh}$ & $30 \%$ & $1919.87 \mathrm{~kg}$ \\
\hline
\end{tabular}

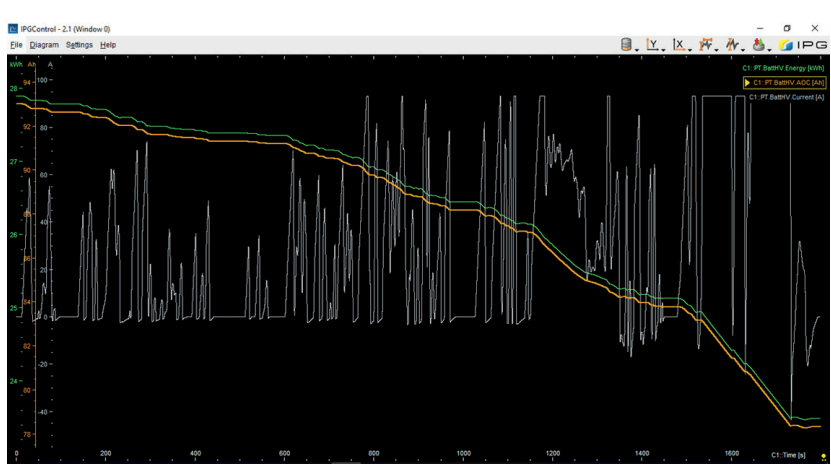

Fig. 2 Battery current and energy monitored in IPGControl 


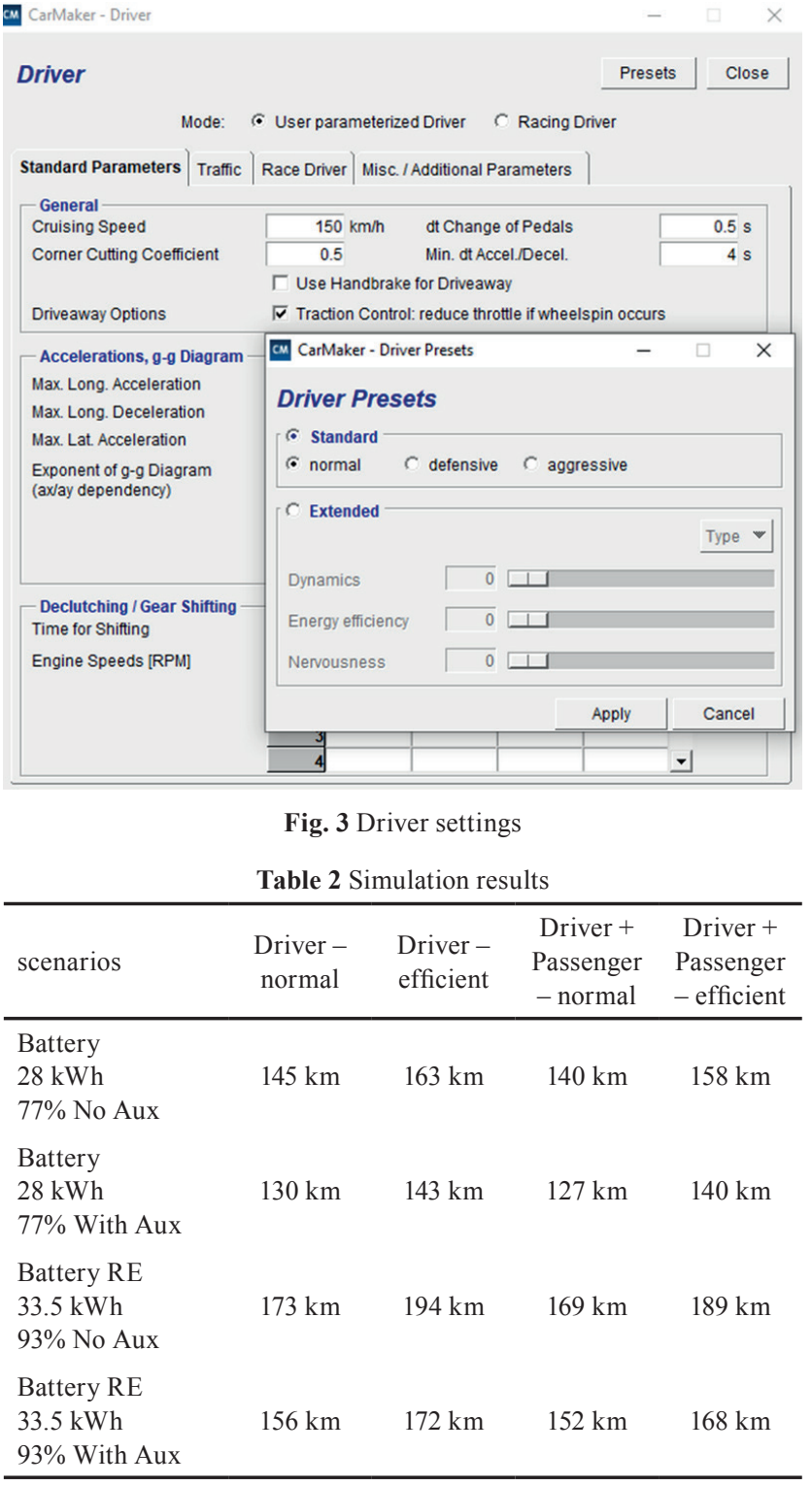

\subsection{Vehicle test drive}

At the Automotive Technologies Department, of the Vehicle Engineering Faculty of Budapest University of Technology and Economics, we have a Mercedes-Benz Class B 250e. We previously created a model in IPG CarMaker, simulated the vehicle under the WLTP test cycle, and we got the consumption figures and the estimated range. We decided to test the vehicle in real driving circumstances, a mixture of highway, city driving, traffic jams, and then compared the results with the simulation figures (Fig. 4).

- Prior to the test, the vehicle was fully charged.

- A diagnosis was performed to check any faults in the vehicle's different ECUs and systems.

- The driving part of the test was conducted at an ambient temperature of $6-8{ }^{\circ} \mathrm{C}$.
- The test was conducted with a driver and front passenger.

- The climate control was set to auto and headlights were switched on at first stage, then the $\mathrm{A} / \mathrm{C}$ was turned off.

- The normal driving mode was selected (efficiency mode "98 kW").

- The regenerative braking was set to $D$ (moderate recuperation).

- The driving was performed in a mixture of city driving with different traffic situations (this simulates Stop \& Start situations), on a country road then on a motorway.

- The range extender was not used $(28 \mathrm{kWh}$ battery only). Test drive results are presented in Table 3.

\section{Results}

The Mercedes-Benz B 250e was simulated with IPG CarMaker and tested under the WLTP test procedure. To bring the vehicle's range into real world challenge it was driven in a mixture of roads and traffic conditions

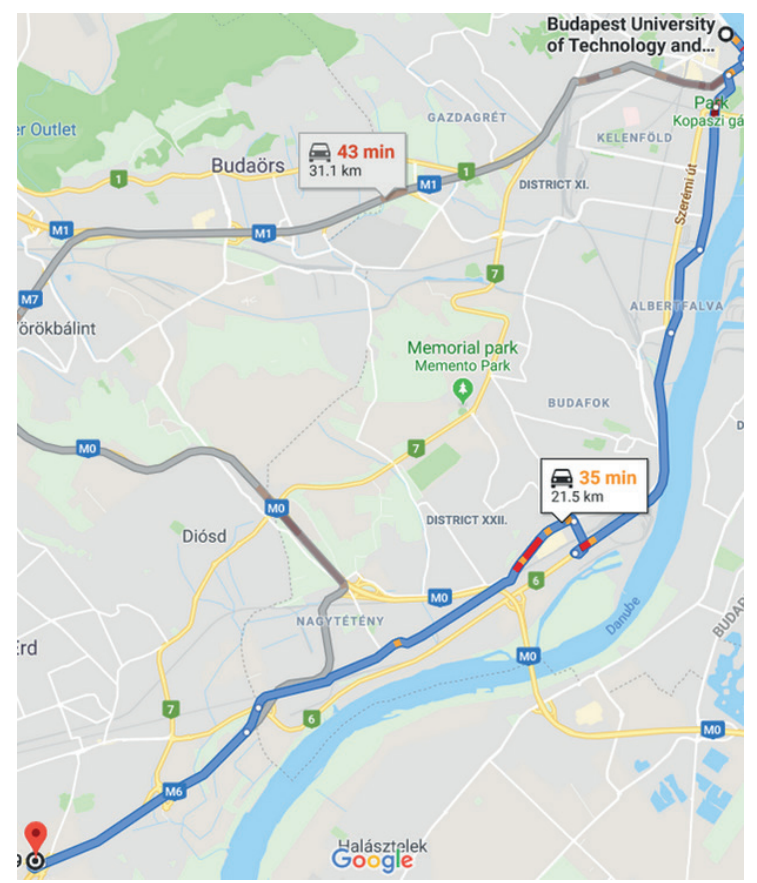

Fig. 4 Driving test cycle

Table 3 Test drive results

\begin{tabular}{lcc}
\hline & Consumption & Regeneration \\
\hline $\mathrm{A} / \mathrm{C} \mathrm{ON}$ & $22.76 \mathrm{kWh} / 100 \mathrm{~km}$ & $17.86 \%$ \\
$\mathrm{~A} / \mathrm{C} \mathrm{OFF}$ & $21.30 \mathrm{kWh} / 100 \mathrm{~km}$ & $33.66 \%$ \\
City Driving & $18.26 \mathrm{kWh} / 100 \mathrm{~km}$ & $18 \%$ \\
\hline
\end{tabular}

A/C takes usually $1.5-2 \mathrm{kWh}$

Average Consumption: $20.78 \mathrm{kWh} / 100 \mathrm{~km} \sim 134 \mathrm{~km}$ range. 
and we checked whether we could really reach the distance promoted by the manufacturer and what the percentage difference between the previous NEDC test and the new WLTP was.

These were the main questions we tried to answer in this paper. The main results are compared in Table 4.

The $140 \mathrm{~km}$ threshold could only be reached following our simulation in the case of an energy efficient driver or with A/C Off and minimum auxiliaries usage.

From Simulation Results:

- In the case of two passengers weighing over $140 \mathrm{~kg}$ in average, and a normal driver we got $140 \mathrm{~km}$ (127 km with Aux) with a $28 \mathrm{kWh}$ battery, with Range Extended to $33.5 \mathrm{kWh}$ battery around $169 \mathrm{~km}$ (152 km with Aux).

- In the case of two passengers weighing over $140 \mathrm{~kg}$ in average, and an energy efficient driver we got $158 \mathrm{~km}$ (140 km with Aux) with a $28 \mathrm{kWh}$ battery, with Range Extended to $33.5 \mathrm{kWh}$ battery around 189 km (168 km with Aux).

WLTP test is very close to EPA (US) rating for the MB 250e. On the other hand, NEDC gives the MB250e $200 \mathrm{~km}$, but overall the performances are good in this vehicle category. In general, NEDC range decreases by around $20-25 \%$ when testing according to WLTP.

The range you get in an EV depends on several parameters, mainly, the battery capacity, weight and load, auxiliaries, driving style and environment.

\section{Discussion and conclusion}

Lot of ongoing parallel researches are conducted to understand and to be able to predict the mileage of electric vehicles. Most of the researches are focusing on a single factor that influences the energy consumption. Charge level

\section{References}

Antonya, C., Butnariu, S., Beles, H. (2015) "Parameter Estimation from Motion Tracking Data", In: Digital Human Modeling. Applications in Health, Safety, Ergonomics and Risk Management: Ergonomics and Health (DHM 2015), Los Angeles, CA, USA, pp. 113-121. https://doi.org/10.1007/978-3-319-21070-4_12

Baum, M., Dibbelt, J., Pajor, T., Wagner, D. (2016) "Dynamic Time-Dependent Route Planning in Road Networks with User Preferences", In: Experimental Algorithms (SEA 2016), St. Petersburg, Russia, pp. 33-49. https://doi.org/10.1007/978-3-319-38851-9_3

Bi, J., Wang, Y., Shao, S., Cheng, Y. (2018) "Residual range estimation for battery electric vehicle based on radial basis function neural network", Measurement, 128, pp. 197-203. https://doi.org/10.1016/j.measurement.2018.06.054
Table 4 Test results comparison

\begin{tabular}{lccc}
\hline NEDC Rating & $\begin{array}{c}\text { WLTP Rating } \\
\text { (Simulation) }\end{array}$ & $\begin{array}{c}\text { Test Drive } \\
\text { Range }\end{array}$ & EPA Rating \\
\hline $200 \mathrm{~km}$ & $127 \mathrm{~km}$ & $134 \mathrm{~km}$ & $140 \mathrm{~km}$ \\
\hline
\end{tabular}

of battery estimation (SOC) gives a special importance to mileage estimation, and up to now only a limited number of papers have been presented with the aim to merge all influencing factors on electric vehicle fuel consumption and range prediction. Handling different aspects as driver behavior or environmental effects jointly within a single model should be the main focus of future studies. Furthermore, rising awareness among drivers or potential customers on how their vehicles behave, how their personal consumption or auxiliaries usage control the range they can reach is crucial to improve the EV's adoption rate and minimize range anxiety:

- It was always obvious that the OEM communicated values are conservative and could only be achieved with a highly efficient driving style as well as energy consumption awareness.

- Electric vehicle owners must be conscious of environmental conditions and be ready to reduce mileage during high or low temperature periods.

- Utilization of heating, ventilation, and air conditioning should be limited to minimize their effect on driving distance and equivalent energy economy.

- Heating, ventilation, and air conditioning and auxiliaries excessive usage can lead to $30 \%$ of range lose. $18-22 \mathrm{~km}$ were lost in our simulation.

- An aggressive driving style can result in around $20 \%$ of range lose. In our simulation 15-20 km were lost in normal driving vs efficient driving mode, for a more aggressive behavior more mileage can be lost.

Delling, D., Goldberg, A. V., Pajor, T., Werneck, R. F. (2015) "Customizable Route Planning in Road Networks", Transportation Science, 51(2), pp. 566-591. https://doi.org/10.1287/trsc.2014.0579

Gao, T., Erokhin, V., Arskiy, A. (2019) "Dynamic Optimization of Fuel and Logistics Costs as a Tool in Pursuing Economic Sustainability of a Farm", Sustainability, 11(19), Article number: 5463. https://doi.org/10.3390/su11195463

Ivković, I., Čokorilo, O., Kaplanović, S. (2018) "The Estimation of GHG Emission Costs in Road and Air Transport Sector: Case Study of Serbia", Transport, 33(1), pp. 260-267. https://doi.org/10.3846/16484142.2016.1169557 
Javanmardi, S., Bideaux, E., Trigui, R., Nicouleau-Bourles, E., Dehoux, S., Mathieu, H. (2017) "Effect of trajectory optimization parameters on energy consumption and $\mathrm{CO}_{2}$ emissions for a gasoline powered vehicle", Journal of Earth Sciences and Geotechnical Engineering, 7(1), pp. 263-276.

Mruzek, M., Gajdáč, I., Kučera, L., Barta, D. (2016) "Analysis of Parameters Influencing Electric Vehicle Range", Procedia Engineering, 134, pp. 165-174. https://doi.org/10.1016/j.proeng.2016.01.056

Oliva, J. A., Weihrauch, C., Bertram, T. (2013) "Model-based remaining driving range prediction in electric vehicles by using particle filtering and Markov chains", In: 2013 World Electric Vehicle Symposium and Exhibition (EVS27), Barcelona, Spain, pp. 1-10. https://doi.org/10.1109/EVS.2013.6914989

Polak, F. (2018) "E-REV's Hybrid Vehicle Range Modeling", Journal of KONES Powertrain and Transport, 25(2), pp. 281-286. https://doi.org/10.5604/01.3001.0012.2814

Sentoff, K. M., Aultman-Hall, L., Holmén, B. A. (2015) "Implications of driving style and road grade for accurate vehicle activity data and emissions estimates", Transportation Research Part D: Transport and Environment, 35, pp. 175-188. https://doi.org/10.1016/j.trd.2014.11.021

Široký, J., Schroder, S., Gašparík, J. (2017) "Comparison of Operational and Economic Aspects of Direct Road Transport and Continental Combined Transport", Komunikácie: Communications (Scientific Letters of the University of Žilina), 19(2), pp. 109-115.

Török, Á., Zöldy, M. (2010) "Energetic and Economical Investigation of Greenhouse Gas Emission of Hungarian Road Transport Sector", Pollack Periodica, 5(3), pp. 123-132. https://doi.org/10.1556/Pollack.5.2010.3.10
Török, Á., Török, Á., Heinitz, F. (2014) "Usage of Production Functions in the Comparative Analysis of Transport Related Fuel Consumption", Transport and Telecommunication Journal, 15(4), pp. 292-298.

https://doi.org/10.2478/ttj-2014-0025

Varga, B. O., Sagoian, A., Mariasiu, F. (2019) "Prediction of Electric Vehicle Range: A Comprehensive Review of Current Issues and Challenges", Energies, 12(5), Article number: 946.

https://doi.org/10.3390/en12050946

Yuksel, T., Michalek, J. J. (2015) "Effects of Regional Temperature on Electric Vehicle Efficiency, Range, and Emissions in the United States", Environmental Science and Technology, 49(6), pp. 3974-3980 https://doi.org/10.1021/es505621s

Ziebart, B. D., Maas, A., Bagnell, J. A., Dey, A. K (2008) "Maximum Entropy Inverse Reinforcement Learning", In: Proceedings of the Twenty-Third AAAI Conference on Artificial Intelligence, Chicago, IL, USA, pp. 1433-1438.

Zöldy, M. (2009) "Potential future renewable fuel challenges for internal combustion engine", Járművek és Mobilgépek, 2(4), pp. 397-403.

Zöldy, M. (2018) "Legal Barriers of Utilization of Autonomous Vehicles as Part of Green Mobility", In: Proceedings of the 4th International Congress of Automotive and Transport Engineering (AMMA 2018), Cluj-Napoca, Romania, pp. 243-248. https://doi.org/10.1007/978-3-319-94409-8_29

Zöldy, M. (2019) "Improving Heavy Duty Vehicles Fuel Consumption with Density and Friction Modifier", International Journal of Automotive Technology, 20(5), pp. 971-978. https://doi.org/10.1007/s12239-019-0091-y 